\title{
Actinorhodin is a Chromosomally-determined Antibiotic in Streptomyces coelicolor A3(2)
}

\author{
By L. F. WRIGHT* AND D. A. HOPWOOD \\ John Innes Institute, Colney Lane, Norwich NR4 $7 \mathrm{UH}$
}

(Received 23 February 1976)

\begin{abstract}
SUMMARY
Streptomyces coelicolor A3(2) synthesizes a second antibiotic, in addition to the plasmid-determined methylenomycin A. It was identified, primarily on the evidence of mass spectroscopy of its diethyl ester, as actinorhodin, which has been described previously in other strains. It inhibited most Gram-positive bacteria tested, but only at a comparatively high concentration. Five independent mutations leading to lack of actinorhodin synthesis were located between $c y s D$ and $\operatorname{str} A$ on the chromosome.
\end{abstract}

\section{INTRODUCTION}

Brockmann \& Pini (I947) first noted the inhibitory activity of the $\mathrm{pH}$ indicator pigment of Streptomyces coelicolor against Staphylococcus aureus. The antibiotic was named actinorhodin, and its chemical structure was subsequently elucidated (Brockmann et al., I966).

Antibiotic synthesis by $S$. coelicolor A3(2) has recently been described (Kirby, Wright \& Hopwood, 1975; Wright \& Hopwood, 1976), and biosynthetic genes for methylenomycin A were shown to be carried on the SCPI plasmid. We present evidence that $S$. coelicolor A3(2) produces at least one other major antibiotic component, namely actinorhodin, and that there are probably several closely linked chromosomal genes controlling its synthesis.

\section{METHODS}

General. Minimal medium (MM), complete medium (CM) and general techniques were those described by Hopwood (1967). Growth of cultures in liquid CM was as described by Wright \& Hopwood (1976). Nutrient agar was Difco Bacto-nutrient agar. Ultravioletmutagenesis for the isolation of actinorhodin non-producing (act) mutants was by the method of Harold \& Hopwood (1970).

Strains. Streptomyces coelicolor strains (Table I) were mutational and recombinational derivatives of strain A3(2) (Hopwood, I959). The locations on the circular linkage map of the markers used in genetic analysis are shown in Fig. I. Streptomyces coelicolor (violaceoruber) strain 199 (Bradley, 1962) was used in preliminary comparative experiments on actinorhodin production. The strains of micro-organisms used in testing for sensitivity to actinorhodin were the same as those used for methylenomycin (Wright \& Hopwood, 1976).

Staphylococcus aureus NCTC8532 was used routinely in bio-assays of actinorhodin.

Extraction of actinorhodin from liquid cultures of strain $\mathrm{I} 190$. The extraction procedure was that described by Brockmann et al. (1966). Mycelium (66 g), filtered from 31 of culture

\footnotetext{
* Present address: Biological Laboratory, The University, Canterbury, Kent CT2 7NH.
} 
Table I. Derivatives of Streptomyces coelicolor A3(2) used

All strains were from the John Innes Institute culture collection.

\begin{tabular}{clc} 
Strain no. & \multicolumn{1}{c}{ Genetic markers } & Fertility type \\
8 & hisD3 & $\mathrm{SCPI}^{+}$ \\
250 & hisAI guaAI & $\mathrm{SCPI}^{+}$ \\
1190 & hisAI uraAI strAI & $\mathrm{SCPI}^{-}$ \\
$2377^{*}$ & hisAI uraAI strAI act-3 & $\mathrm{SCPI}^{-}$ \\
$2379^{*}$ & hisAI uraAI strAI act-I9 & $\mathrm{SCPI}^{-}$ \\
$2380^{*}$ & hisAI uraAI strAI act-24 & $\mathrm{SCPI}^{-}$ \\
$2381^{*}$ & hisAI uraAI strAI act-27 & $\mathrm{SCPI}^{-}$ \\
2382 & argAI uraAI strAI act-3 & $\mathrm{SCPI}^{-}$ \\
2388 & hisD4 act-I & $\mathrm{SCPI}^{-}$ \\
A700 & proAI argAI cysDI8 & $\mathrm{SCPI}^{-}$
\end{tabular}

* Mutant derivatives of strain 1190 isolated in the course of this work.

$\dagger$ The act-I mutation was previously referred to as redAI.

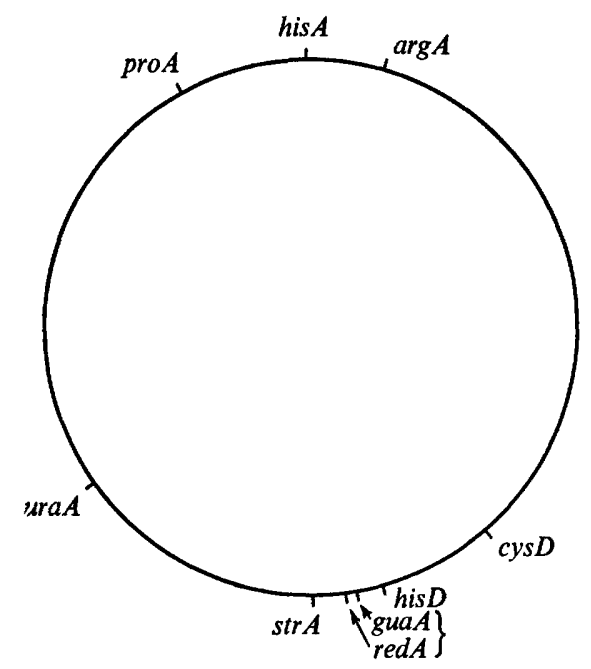

Fig. I. Linkage map of Streptomyces coelicolor A3(2) showing locations of the markers referred to in this paper.

medium, was washed with $61 \mathrm{O} \cdot \mathrm{I} \mathrm{M}-\mathrm{HCl}$ and successively extracted for $2 \mathrm{~h}$ with $330 \mathrm{ml}$ $2 \mathrm{M}-\mathrm{HCl}$ and for $30 \mathrm{~min}$ with $330 \mathrm{ml}$ acetone. After drying in vacuo for 4 to $5 \mathrm{~h}$, the powdered mycelium was ground with 2 vols sand and actinorhodin was extracted in $330 \mathrm{ml} 2 \mathrm{M}-\mathrm{NaOH}$. The supernatant after centrifugation was adjusted to $\mathrm{pH} 3$, and the red precipitate of crude actinorhodin which formed was collected, dried and ground to a powder. Exhaustive extraction with acetone in a Soxhlet extractor for $\mathrm{Io} \mathrm{h}$ left actinorhodin in the thimble. Pure actinorhodin was recovered from this material by extraction and recrystallization using dry $\mathrm{I}, 4$-dioxan. The yield was $\mathrm{I} \cdot 3 \mathrm{~g}$ actinorhodin.

Preparation of actinorhodin diethyl ester. This was prepared according to Brockmann et al. (1966). The presumptive actinorhodin ( $0.75 \mathrm{~g}$ ) was suspended in $20 \mathrm{ml}$ dry I,4-dioxan and heated with Io $\mathrm{ml}$ ethanol saturated with $\mathrm{HCl}$ gas in a sealed glass ampoule at $70^{\circ} \mathrm{C}$ for $7 \mathrm{~h}$ with gentle agitation. After cooling, the residue was filtered off and dried. Recrystallization from benzene gave bright red crystals of the ester. A pure sample of actinorhodin diethyl 


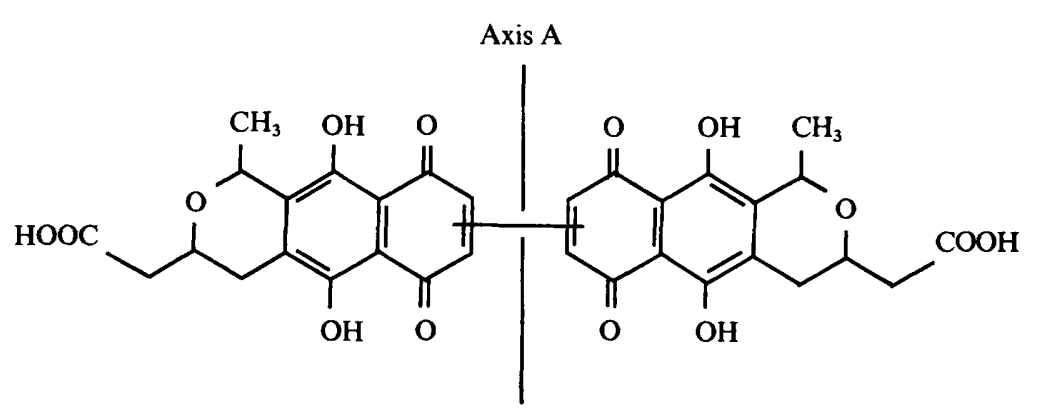

Fig. 2. Actinorhodin. A is the axis of symmetry referred to in the text.

ester was kindly donated by Professor H. Brockmann, Organish-Chemisches Institut, University of Göttingen, Germany, for comparison with our material.

Infrared spectrometry. This was performed with the assistance of Dr J. Boulton, School of Chemical Sciences, University of East Anglia, on a Perkin-Elmer model 237 grating infrared spectrometer (Perkin-Elmer, Beaconsfield, Buckinghamshire).

Mass spectrometry. This was performed by Mr J. Eagles of the Agricultural Research Council Mass Spectrometry Service at the Food Research Institute, Colney Lane, Norwich, using an AEI MS-902 spectrometer at a source temperature of $200{ }^{\circ} \mathrm{C}$ and an ionization energy of $70 \mathrm{eV}$. Accurate masses were obtained at a resolution of 1000 (10\% valley definition), and processed by computer by the method of Johnson, Gordon \& Self (1975).

Isolation of act mutants. Since the initial screening for actinorhodin production involved a test for antibiotic activity, an $\mathrm{SCPI}^{-}$strain was chosen as the parent culture to avoid the complication of methylenomycin production. Another advantage of using $\mathrm{SCPI}^{-}$strains was that they usually produce more actinorhodin than $\mathrm{SCPI}^{+}$strains (R. Kirby \& D. A. Hopwood, unpublished results). Strain I I 90 was a particularly good producer of actinorhodin in solid and liquid media.

Ultraviolet-irradiated spores of several separate cultures of strain I 190 were diluted and plated on CM. The agar plug technique (Ichikawa et al., 197I) was used to detect actinorhodin non-producing (act) mutants. Colony-centred plugs (6 mm diam.) were cut out after incubation for $48 \mathrm{~h}$ and arranged in rows in a $23 \times 23 \mathrm{~cm}$ Bio-Assay dish (Nunc, Roskilde, Denmark). Moist filter paper was used to line the lid of the dish to prevent the plugs from drying during incubation for a further $48 \mathrm{~h}$. Colonies were assayed for production of actinorhodin by pouring nutrient agar seeded with Staph. aureus into the dish.

\section{RESULTS}

\section{Preliminary evidence for a second antibiotic}

It was noted while testing various bacteria for their sensitivity to methylenomycin $A$, the antibiotic determined by the SCPI plasmid, that control SCPI- strains caused inhibition of some bacteria (Wright \& Hopwood, 1976). Bioautography of thin-layer chromatograms of $\mathrm{SCPI}^{+}$and $\mathrm{SCPI}^{-}$culture filtrates also revealed a non-specific area of inhibition that was always located at the origin after running in solvents which moved methylenomycin $\mathrm{A}$. These observations suggested the presence of a second antibiotic, which was produced by $S$. coelicolor A3(2) irrespective of the presence of the SCPI plasmid.

$A$ priori, it was likely that this antibiotic was actinorhodin in view of the resemblance of 


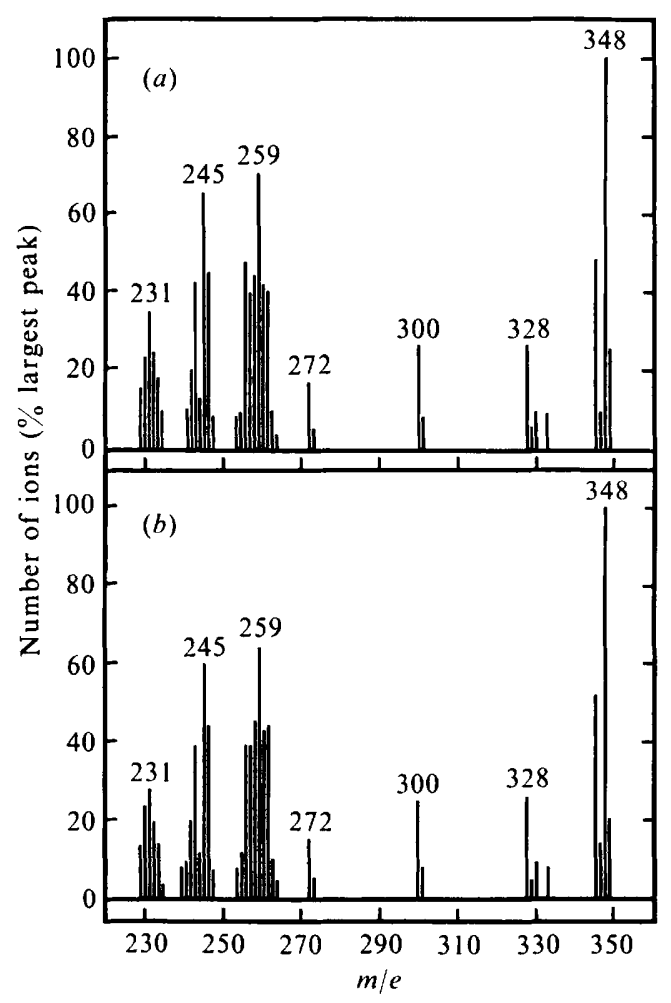

Fig. 3. Mass spectra of actinorhodin diethyl ester: (a) sample donated by Professor H. Brockmann;

(b) sample prepared from $S$. coelicolor A3(2), strain 1190.

$S$. coelicolor A3(2) to known actinorhodin producers, such as Bradley's strain 199 of $S$. coelicolor (violaceoruber), and because colonies of strain A3(2) have red undersides in acid conditions and produce a blue diffusible pigment in alkaline conditions. A comparison of the products in liquid culture of $S$. coelicolor A3(2) strain II90 and Bradley's strain 199 supported this hypothesis. Thin-layer chromatography on silica gel (Kirby, Wright \& Hopwood, 1975) in two solvents [benzene/methanol (95:5, by vol.); acetone/benzene ( $\mathrm{I}: 2$, by vol.)] showed co-migrating pigments in the two strains.

\section{Identification of the pigmented antibiotic of $S$. coelicolor $\mathrm{A3}(2)$}

Crystalline material from liquid-grown mycelium of strain I 190 was compared spectrophotometrically with its diethyl ester and with the diethyl ester of actinorhodin donated by Professor Brockmann. At $100 \mu \mathrm{g} \mathrm{ml}^{-1}$ in $0 \cdot \mathrm{I}_{\mathrm{M}}-\mathrm{NaOH}$, all three substances showed strong absorption peaks at 588 and $632 \mathrm{~nm}$. The infrared spectrum of the presumptive actinorhodin was that expected for a compound with the structure shown in Fig. 2. Strong absorption peaks were located at $3200 \mathrm{~cm}^{-1}$ due to $-\mathrm{OH}$ groups; at $3050 \mathrm{~cm}^{-1}$ due to the two $=\mathrm{CH}$ groups; at 2850 to $2950 \mathrm{~cm}^{-1}$ due to $-\mathrm{COOH}$ groups; at $1725 \mathrm{~cm}^{-1}$ due to carboxylic-acid carbonyl groups; and, notably, a maximum at approximately $1650 \mathrm{~cm}^{-1}$ due to quinone absorption. Quinone absorption is normally at slightly higher wavenumbers ( 1670 to $1690 \mathrm{~cm}^{-1}$ ); the lower value was probably due to extensive hydrogen bonding within the molecule. 
Comparison of the mass spectra of the diethyl esters of the presumptive actinorhodin from strain I 190 and the pure substance confirmed the identity (Fig. 3). When actinorhodin diethyl ester (mol. wt, 690) was heated on the spectrometer probe, the molecule broke in half about the axis of symmetry A shown in Fig. 2. The acquisition of three protons gave the resulting moiety a mass of 348 units and this entity was found to be the $\mathrm{M}^{+}$ion in further breakdown.

\section{The spectrum of antibacterial activity of actinorhodin}

Cultures of strains 1190 and Bradley's 199 were tested by the agar plug method against the bacteria previously tested for sensitivity to methylenomycin (Wright \& Hopwood, 1976). Strains of the following species were inhibited weakly: Bacillus cereus, B. megaterium, B. mycoides, B. subtilis, Micrococcus lysodeikticus and Staphylococcus aureus.

Plugs of CM supplemented with actinorhodin at different concentrations were assayed against Staph. aureus. Extrapolation of the inhibition zones to zero radius indicated a minimum inhibitory concentration of actinorhodin against Staph. aureus of 25 to $30 \mu \mathrm{g} \mathrm{ml}^{-1}$.

The amount of actinorhodin produced in liquid cultures of strain I I 90 incubated for $72 \mathrm{~h}$ in the conditions described was calculated. Although the antibiotic was isolated from mycelium, a convenient way of expressing the antibiotic titre is in $\mu \mathrm{g} / \mathrm{ml}$ culture. It was assumed that there was no actinorhodin dissolved in the medium, since at this $\mathrm{pH}$ (about 6.7) the antibiotic is insoluble and remains localized in or on the mycelium. Assuming no losses during purification, the amount of actinorhodin produced as determined by chemical analysis was $430 \mu \mathrm{g} \mathrm{ml}^{-1}$.

\section{Isolation of act mutants and their phenotypes}

Out of 4075 colonies tested, several produced no inhibition zones and were presumptive act mutants. Five of these gave rise to pure $\mathrm{Act}^{-}$strains on subculture. They were designated $a c t-3, a c t-18, a c t-19, a c t-24$ and act-27. The mutants act-18 and act-19 arose from the same mutagenized culture, and only act- 19 was used in genetic analysis.

Different phenotypes were observed in the mutants: act-3 was pink on the underside of the colonies, act-19 and act-24 were orange and act-27 was reddish-pink. Another mutant (red-r) had been isolated previously (Hopwood, I965) on the basis of altered pigmentation. The available strain carrying red-I (strain $4 \mathrm{II}$ ) was $\mathrm{SCPI}^{+}$. An $\mathrm{SCPI}^{-}$-derivative was isolated after testing u.v.-treated spores of this strain, as described by Vivian \& Hopwood (1970), and on testing against Staph. aureus it did not produce actinorhodin; red-I was therefore renamed act-I. Act ${ }^{+}$and Act $^{-}$colonies, arising through recombination in crosses described below, could be distinguished by means of the $\mathrm{pH}$ indicator properties of actinorhodin. Patches of spores from recombinants arising on selective media were streaked in arrays of 20 per plate on the same medium. After 3 days growth, the patches were replica plated to classify the standard markers. The Act character was scored by placing $5^{\circ} 0 \mathrm{ml}$ ammonia (sp. gr. 0.88) in the lid of the inverted Petri dish. Act ${ }^{+}$patches rapidly changed colour from red to blue, and the blue actinorhodin soon began to diffuse; Act- patches did not change colour. This method was compared with the bio-assay against Staph. aureus of agar plugs cut from the centre of patches, and a complete correlation was found when Ioo colonies were tested. The ammonia test was therefore used routinely because of its simplicity and its resolution in revealing mixed patches containing $\mathrm{Act}^{+}$and $\mathrm{Act}^{-}$colonies. 
Table 2. Recombinant genotypes from crosses of the type hisAI uraAI strAI act $S C P I^{-} \times \mathrm{A} 700$ ( proAI argAI cysDI8 $\mathrm{SCPI}^{-}$): selection was for his ${ }^{+}$and strAI (see Fig. 4)

\begin{tabular}{|c|c|c|c|c|}
\hline Recombinant genotypes* & $2377 \times$ A700 & $2379 \times \mathbf{A} 700$ & $2380 \times A 700$ & $2381 \times A 700$ \\
\hline proAI $\arg A I$ cysDI8 uraAI strAI & 5 & 0 & o & 7 \\
\hline proAI argAI cysDI8 uraAI strAI act & 3 & 0 & I & 0 \\
\hline proAI argAI cys DI8 strAI & 147 & I & 3 & 80 \\
\hline proAI $\arg A I$ cys DI 8 strAI act & 102 & 2 & I & 0 \\
\hline proAI arg AI uraAI strAI act & 18 & 4 & 6 & 2 \\
\hline $\arg A I$ cys $D I 8$ uraAI strAI & 0 & $\overrightarrow{0}$ & 0 & 3 \\
\hline proAI $\arg A I$ strAI act & 84 & 60 & $7 \mathrm{I}$ & 7 \\
\hline proAI uraAI strAI act & 0 & 2 & I & 0 \\
\hline $\arg A I$ uraAI strAI act & 4 & 6 & 5 & I \\
\hline proAI strAI act & 0 & 4 & 2 & 0 \\
\hline proAI $\arg A I$ strAI† & 0 & I & 0 & 0 \\
\hline proAI cysDI8 strAI act $\dagger$ & 0 & I & 0 & 0 \\
\hline $\arg A I \operatorname{str} A I$ act $\dagger$ & 0 & I & 0 & 0 \\
\hline Totals $*$ wild-tyne alleles omitted & 363 & 82 & 90 & 100 \\
\hline
\end{tabular}

\section{Genetic analysis of act mutants}

Crosses of the type $\mathrm{SCPI}^{-} \times \mathrm{SCPI}^{-}$were used in preliminary genetic analysis to avoid the presence of methylenomycin. These have a low fertility but are typically non-polarized, each parent acting as donor in some zygotes and as recipient in others (Hopwood et al., 1973). This provides a convenient situation for preliminary mapping, just as in NF $\times \mathrm{NF}$ crosses (Hopwood, 1967).

Initial mapping of act-3, act-19, act-24 and act-27 was done by crossing each of the strains 2377, 2379, 2380, and 238I (hisAI uraAI strAI act) with strain A700 (proAI argAI cysDI8). The data are in Table 2. Allele frequencies (Fig. 4) gave possible locations for act-3, act-I9 and $a c t-24$ between str $A$ and $u r a A$, or between cys $D$ and str $A$. To minimize quadruple crossing-over classes, the mutations were placed in the latter region (see the tests of independence in Fig. 4). The act-27 mutation was also located anticlockwise of $s t r A$ by these criteria but no recombination occurred between act-27 and $\operatorname{cys} D$.

A recombinant from the $2377 \times \mathrm{A} 700$ cross (strain 2382 ; $\arg A I$ uraAI strAI act-3) was crossed in duplicate to strain $8\left(\right.$ his $\left.D_{3}\right)$. Evidence for a map location between $\operatorname{str} A$ and his $D$ came from the allele frequencies for the combined data (Fig. 5) and the finding of five recombinants of genotype act-3 his D and none of the complementary act $t^{+}$his $^{+}$genotype (Table 3). The guaA locus lies between his $D$ and $\operatorname{str} A$ (Fig. I). Sixty recombinants inheriting $\arg A^{+}$and $\operatorname{str} A$ selected from a cross of strains 2382 and 250 (hisAI guaAI) showed no recombination between guaA and act-3.

A previous investigation had mapped the act-I ( $\operatorname{redAI})$ mutation between his D and strA (Hopwood, I965). Mapping of the act-I mutation with respect to guaA was attempted by crossing strain 2388 (his $D_{4}$ act-I) with strain 250, with selection for his $A^{+}$and his $D^{+}$. Out of 96 progeny, none showed recombination between act-I and guaA, as in the cross between strain 2382 and strain 250 . 
(a)

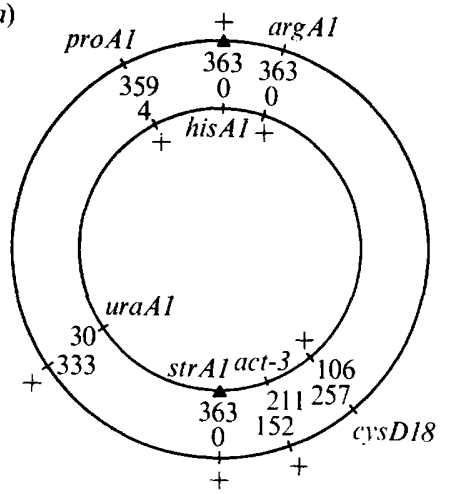

(b)

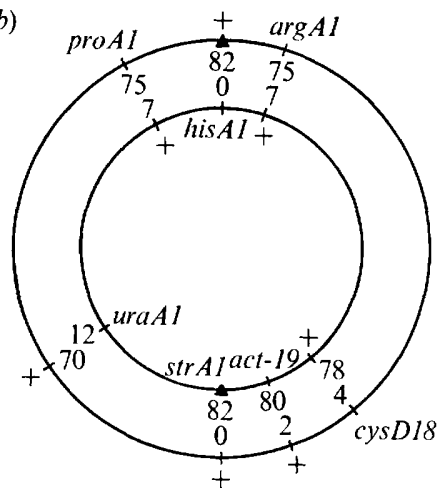

\begin{tabular}{|c|c|c|c|c|c|}
\hline & cys $^{+}$ & cys-I 8 & & $u r a^{+}$ & ura-I \\
\hline$a c t^{+}$ & 0 & I52 & $a c t^{+}$ & 147 & 5 \\
\hline$a c t-3$ & 106 & 105 & act -3 & I 86 & 25 \\
\hline
\end{tabular}

(c)

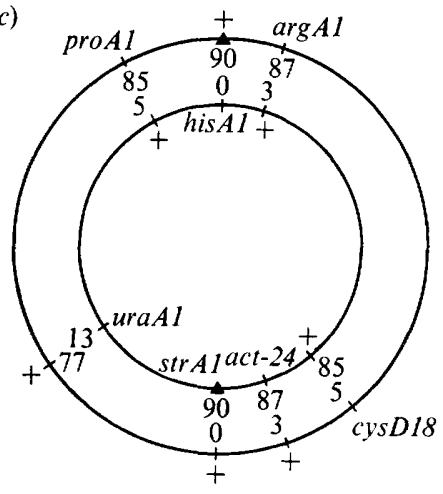

\begin{tabular}{|c|c|c|c|c|c|}
\hline & $c y s^{+}$ & cys-I 8 & & $\mathrm{ura}^{+}$ & ura-I \\
\hline$a c t^{+}$ & 0 & 3 & $a c t^{+}$ & 3 & 0 \\
\hline act-24 & 85 & 2 & $a c t-24$ & 74 & 13 \\
\hline
\end{tabular}

\begin{tabular}{|c|c|c|c|c|c|}
\hline & $c^{\prime} y s^{+}$ & cys-18 & & $\mathrm{ura}^{+}$ & ura-I \\
\hline$a c t^{+}$ & I & I & $a c t^{+}$ & 2 & 0 \\
\hline act-I9 & 77 & 3 & act-Ig & 68 & I 2 \\
\hline
\end{tabular}

(d)

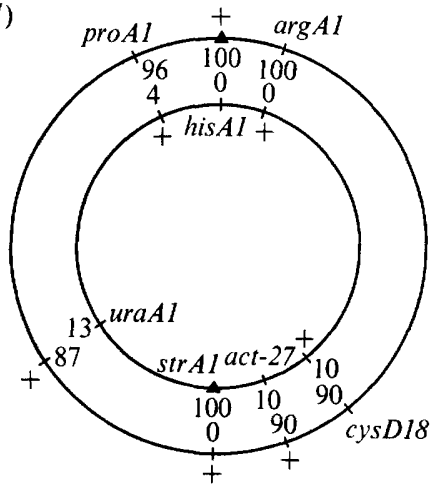

\begin{tabular}{|c|c|c|c|c|c|}
\hline & cys $^{+}$ & cys $-x 8$ & & $\mathrm{ura}^{+}$ & ura-I \\
\hline$a c t^{+}$ & 0 & 90 & $a c t^{+}$ & 80 & 10 \\
\hline$a c t-27$ & IO & 0 & act -27 & 7 & 3 \\
\hline
\end{tabular}

Fig. 4. Interpretation of crosses designed to determine the locations of act mutations. Strains (a) $2377,(b) 2379,(c) 2380$ and (d) 238I (inner circles) were each crossed with strain A700 (outer circles) and the alleles $h i s A^{+}$and $\operatorname{str} A I$ (indicated $\boldsymbol{\Delta}$ ) were selected. The allele ratio for each $a c t$ mutation is compatible with a location between $\operatorname{str} A$ and $u r a A$ or between $\operatorname{cys} D$ and $\operatorname{str} A$. Analyses of the segregation of act in relation to that of ura or of cys (see the $2 \times 2$ tabulations) indicate a position between $\operatorname{cys} D$ and $\operatorname{str} A$ (or close to $\operatorname{cys} D$ in the case of cross $d$ ). The frequencies of individual recombinant genotypes are given in Table 2.

\section{DISCUSSION}

Streptomyces coelicolor A3(2) produces the pigmented antibiotic actinorhodin, previously studied chemically by Brockmann et al. (I966). Apart from the observation that actinorhodin inhibited Staph. aureus, its range of antibiotic activity and the genetic determination of its synthesis were unknown.

All the mutations leading to loss of actinorhodin synthesis mapped in the same region of the $\mathrm{A}(3) 2$ linkage map, between $c y s D$ and $\operatorname{str} A$. Since different mutants showed various types of pigmentation, it is unlikely that the mutations are all allelic. The isolation and mapping of more mutations and, if possible, the application of complementation tests would permit 
Table 3. Recombinant genotypes from duplicate crosses of strain 2382 (argAI uraAI str $A$ I act-3 $S C \mathrm{PI}^{-}$) with strain 8 (his $\left.D_{3} S C \mathrm{PI}^{+}\right)$: selection was for $\arg A^{+}$and str $A I$ (see Fig. 5)

\begin{tabular}{|c|c|c|c|}
\hline \multirow[b]{2}{*}{ Recombinant genotypes* } & \multicolumn{3}{|c|}{ Number from each cross } \\
\hline & A & B & Total \\
\hline his $D_{3}$ uraAr strAI & I & 2 & 3 \\
\hline his $D_{3}$ uraAI strAI act-3 & I & $\mathbf{I}$ & 2 \\
\hline his $D_{3} \operatorname{str} A I$ & 13 & 24 & 37 \\
\hline his $D_{3}$ str $A$ I act-3 & I & 2 & 3 \\
\hline uraAI strAI act-3 & 50 & 62 & II 2 \\
\hline str $A I$ act -3 & 34 & 40 & 74 \\
\hline Totals & 100 & I3I & $23 I$ \\
\hline
\end{tabular}

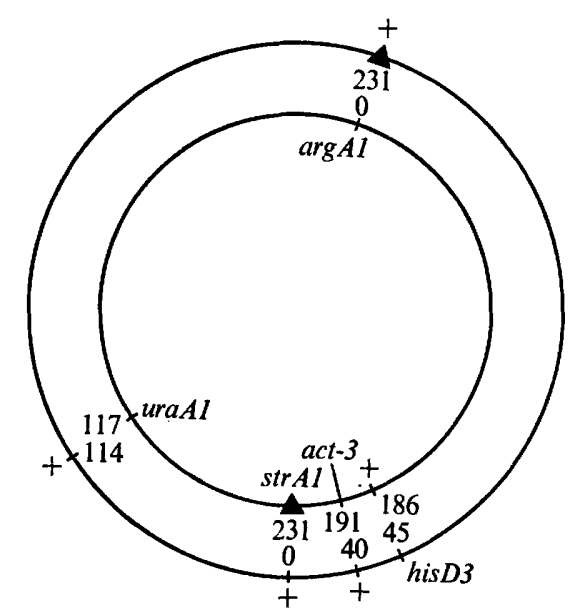

Fig. 5. Interpretation of a cross designed to locate act-3 with respect to his $D$. Strain 2382 (inner circle) was crossed with strain 8 (outer circle) and the alleles $\arg A^{+}$and $\operatorname{str} A I$ (indicated $\Delta$ ) were selected. The allele ratio for act-3 indicates a location between $\operatorname{str} A$ and his $D$. The frequencies of individual recombinant genotypes are given in Table 3.

exploration of the possibility that a gene cluster is involved in actinorhodin synthesis. Remarkably little is yet known about the organization of genes controlling antibiotic synthesis, and actinorhodin in $S$. coelicolor A3(2) may provide an illuminating model system for such a study, particularly since the important polyketide route is likely to be involved in actinorhodin synthesis (Brockmann et al., I966).

Actinorhodin inhibited the growth of some Gram-positive bacteria although its activity was low. The minimum inhibitory concentration of actinorhodin against Staph. aureus was 25 to $30 \mu \mathrm{g} \mathrm{ml}^{-1}$.

Perhaps it is significant that actinorhodin, an antibiotic of low activity, is produced in large quantities by a wild-type strain of $S$. coelicolor. The calculated figure was at least $430 \mu \mathrm{g} \mathrm{ml}^{-1}$, which contrasts with Io to $50 \mu \mathrm{g}$ penicillin $\mathrm{ml}^{-1}$ for Penicillium notatum wildtypes (Alikhanian, 1962) and 50 to $100 \mu \mathrm{g}$ streptomycin $\mathrm{ml}^{-1}$ for Streptomyces griseus (Schatz \& Waksman, 1945). If antibiotic production is adaptive in increasing the competitive advantage of microbes in areas of high nutrient concentration (Garrett, 1956; Brian, 1957), the 
producing organism might have evolved a high level of production to compensate for the weak activity of the antibiotic.

It is not unusual to find that a single Streptomyces strain produces more than one antibiotic. A novel situation exists, however, in S. coelicolor A3(2) where, of the two antibiotics so far discovered, one, methylenomycin, is plasmid determined (Kirby, Wright \& Hopwood, I975; Wright \& Hopwood, I976) and the other, actinorhodin, is chromosomally determined.

One of us (L.F.W.) is grateful to the Agricultural Research Council for a Postgraduate Studentship.

\section{REFERENCES}

Alikhanian, S. I. (1962). Induced mutagenesis in the selection of microorganisms. Advances in Applied Microbiology 4, I-50.

BRADLEY, S. G. (1962). Biosynthesis of an actinorhodin-like pigment by Streptomyces violaceoruber. Developments in Industrial Microbiology 3, 362-369.

BRIAN, P. W. (1957). The ecological significance of antibiotic production. In Microbial Ecology, pp. I68-I88. Edited by R. E. O. Williams and L. C. Spicer. Cambridge University Press.

BrockmanN, H. \& Pin, H. (I947). Actinorhodin, ein roter Farbstoff aus Actinomyceten. Naturwissenschaften 34, I90.

Brockmann, H., Zeeck, A., van DER Merwe, K. \& Müller, W. (1966). Die Konstitution des Actinorhodins. Justus Liebigs Annalen der Chemie 698, 209-229.

GARRETT, S. D. (1956). The Biology of Root-infecting Fungi. Cambridge University Press.

HAROLD, R. J. \& HOPWOOD, D. A. (1970). Ultraviolet-sensitive mutants of Streptomyces coelicolor. I. Phenotypic characterization. Mutation Research ro, 427-438.

Hopwood, D. A. (1959). Linkage and the mechanism of recombination in Streptomyces coelicolor. Annals of the New York Academy of Sciences 8r, 887-898.

Hopwood, D. A. (1965). New data on the linkage map of Streptomyces coelicolor. Genetical Research, Cambridge 6, 248-262.

Hopwood, D. A. (1967). Genetic analysis and genome structure in Streptomyces coelicolor. Bacteriological Reviews 31, 373-403.

Hopwood, D. A., Chater, K. F., Dowding, J. E. \& Vivian, A. (1973). Advances in Streptomyces coelicolor genetics. Bacteriological Reviews 37, 37I-405.

ICHIKAWA, T., DaTE, M., IshikURA, T. \& OZAKI, A. (197I). Improvement of kasugamycin-producing strain by the agar piece and the prototroph method. Folia microbiologica 16, 218-224.

Johnson, M. W., GoRdon, B. J. \& SelF, R. (1975). Mass-spectral data processing using a general purpose computer. Laboratory Practice, 267-27I.

KIRBY, R., WRIGHT, L. F. \& HOPWOOD, D. A. (1975). Plasmid determined antibiotic synthesis and resistance in Streptomyces coelicolor. Nature, London 254, 265-267.

SChATZ, A. \& WAKSMAN, S. A. (1945). Strain specificity and production of antibiotic substances. IV. Variations among actinomycetes, with special reference to Streptomyces griseus. Proceedings of the National Academy of Sciences of the United States of America 31, I29-137.

VIvian, A. \& HopwOod, D. A. (1970). Genetic control of fertility in Streptomyces coelicolor A3(2): the IF fertility type. Journal of General Microbiology 64, I0I-117.

WRIGHT, L. F. \& Hopwood, D. A. (I976). Identification of the antibiotic determined by the SCPI plasmid of Streptomyces coelicolor A3(2). Journal of General Microbiology 95, 96-106. 